OPEN ACCESS

Edited by:

Anna Ohradanova-Repic,

Medical University of Vienna, Austria

Reviewed by:

Andreas Diefenbach,

Charité University Medicine, Germany Arthur Mortha

University of Toronto, Canada

*Correspondence:

Tim Willinger

tim.willinger@ki.se

Specialty section:

This article was submitted to NK and Innate Lymphoid Cell Biology,

a section of the journal

Frontiers in Immunology

Received: 22 March 2019

Accepted: 08 August 2019

Published: 22 August 2019

Citation:

Willinger T (2019) Metabolic Control of Innate Lymphoid Cell Migration.

Front. Immunol. 10:2010.

do: $10.3389 /$ fimmu.2019.02010

\section{Metabolic Control of Innate Lymphoid Cell Migration}

\author{
Tim Willinger*
}

Department of Medicine Huddinge, Center for Infectious Medicine, Karolinska Institutet, Stockholm, Sweden

Innate lymphoid cells (ILCs) are specialized immune cells that rapidly respond to environmental challenges, such as infection and tissue damage. ILCs play an important role in organ homeostasis, tissue repair, and host defense in the mucosal tissues intestine and lung. ILCs are sentinels of healthy tissue function, yet it is poorly understood how ILCs are recruited, strategically positioned, and maintained within tissues. Accordingly, ILC migration is an area that has recently come into focus and it is important to define the signals that control ILC migration to and within tissues. In this context, signals from the local tissue microenvironment are relevant. For example, ILCs in the intestine are exposed to an environment that is rich in dietary, microbial, and endogenous metabolites. It has been shown that the Vitamin A metabolite retinoic acid promotes ILC1 and ILC3 homing to the intestine. In addition, recent studies have discovered cholesterol metabolites (oxysterols) as a novel class of molecules that regulate ILC migration through the receptor GPR183. ILCs are considered to be largely tissue-resident cells, yet recent data indicate that ILCs actively migrate during inflammation. Furthermore, the discovery of circulating ILC precursors in humans and their presence within tissues has fueled the concept of local ILC-poiesis. However, it is unclear how circulating ILCs enter tissue during embryogenesis and inflammation and how they are directed to local tissue niches. In this review, I will discuss the metabolic signals that regulate ILC homing and their strategic positioning in healthy and inflamed tissues. It is becoming increasingly clear that ILC function is closely linked to their tissue localization. Therefore, understanding the tissue signals that control ILC migration could open new avenues for the treatment of chronic inflammatory diseases and cancer.

Keywords: innate lymphoid cells, migration, metabolism, oxysterol, inflammation, cancer

\section{BACKGROUND}

Innate lymphoid cells (ILCs) are immune cells of lymphoid origin that quickly respond to perturbations of tissue homeostasis. Apart from their role in barrier immunity and host defense, ILCs are also essential for organ homeostasis, recovery from tissue injury, and metabolism (1-5). In addition to cytotoxic natural killer (NK) cells, three different ILC types can be distinguished based on signature transcription factors and effector cytokines, similar to $\mathrm{CD} 4^{+} \mathrm{T}$ helper lymphocytes: (1) $\mathrm{T}_{-} \mathrm{BET}^{+}$ILC1s produce interferon-gamma (IFN $\gamma$ ); (2) GATA $3{ }^{\text {high }}$ ILC2s produce interleukin-5 (IL-5) and IL-13; (3) ROR $\gamma \mathrm{t}^{+}$ILC3s produce IL-17 and/or IL-22. ROR $\gamma \mathrm{t}^{+}$ILC3s include fetal lymphoid tissue-inducer (LTi) cells and adult LTi-like cells that have a similar phenotype $\left(\mathrm{CCR} 6^{+} \mathrm{NKp} 46^{-}\right)$and mainly reside in lymphoid tissues $(6,7)$. LTi cells are now considered a separate ILC lineage due to their unique ontogeny $(5,8) . \alpha 4 \beta 7^{+}$CXCR $6^{+}$ILC3 precursors (ILC3Ps) 
develop into LTi cells in the fetal liver (9). In contrast, adult LTi-like ILC3s can derive from bone marrow precursors that upregulate ROR $\gamma \mathrm{t}$ in peripheral tissues, such as the intestine, in a Notch-dependent manner (9). Perinatal ROR $\gamma t^{+}$ILCs give rise to long-lived ILC3s in the small intestine (10), yet it is unclear whether and to what extent embryonic LTi cells persist in the adult. Therefore, the developmental relationship between fetal LTi cells and adult LTi-like ILC3s remains to be defined. Adult mice also have T-BET-expressing CCR6 ${ }^{-} \mathrm{NKp} 46^{+}$ ILC3s that are derived from CCR6 ${ }^{-} \mathrm{NKp} 46^{-}$ILC3s (11). Dietary phytochemicals acting through the aryl hydrocarbon receptor (AHR) are required for the post-natal expansion of these CCR6 ${ }^{-}$ adult ILC3s (12-14). Both fetal LTi cells (15) and adult ILC3s in the intestine $(16,17)$ are dependent on the Vitamin A metabolite retinoic acid.

Many features of ILCs are shared with T cells, but ILCs also have unique, non-redundant, functions, such as the ability to orchestrate the formation of lymphoid tissues, which is carried out by ILC3s with LTi function $(12,13,18-21)$. In mice, the prenatal formation of lymphoid tissues (lymph nodes and Peyer's Patches) is carried out by $\mathrm{CD}^{+}$fetal LTi cells, whereas adult ILC3s mediate the development of intestinal cryptopatches and isolated lymphoid follicles that develop after birth $(22,23)$. Besides their beneficial effects, ILCs have been implicated in chronic inflammatory responses that underlie human disease (24-26).

The main focus in the research on ILCs has been on cell lineage relationships, transcription factors, and effector function-mostly based on analogies with $\mathrm{T}$ lymphocytes. ILC migration has only recently become an active area of investigation. Their strategic position within tissues allows ILCs to fulfill their role as sentinels of healthy tissue function. Furthermore, local ILC clustering and rapid migration in response to inflammatory signals may explain why ILCs exert such powerful effects on tissue immunity (Figures 13). However, much remains to be learned about the pathways that regulate the migration and tissue localization of ILCs. In this review, I mainly discuss the migration of ILCs other than NK cells.

\section{TISSUE DISTRIBUTION OF ILCs}

ILCs are found in many organs, but are enriched in mucosal tissues (intestine, lung) that are most exposed to the environment (10, 16, 27-31). Furthermore, the relative abundance of ILC subsets differs between tissues in mice $(10,16,28)$ and humans $(30,31)$, with ILCs perhaps less compartmentalized in humans than in mice (31). For example, ILC3s are abundant in the small intestine and ILC2s in the skin as well as in adipose tissue, whereas NK cells predominate in bone marrow, spleen, liver, and lung (32). In addition, there are regional differences in ILC distribution within the same organ. For example, NKp46 ${ }^{+}$ILC3s are enriched in the small intestine, whereas in the colon adult LTi-like ILC3s are more prevalent. In addition, ILC2s are more abundant in the colon than in the small intestine (32). Moreover, ILC abundance differs between steady-state and inflamed tissue
(33-35). Finally, developmental age of the organism influences ILC tissue distribution. For example, LTi-like ILC3s are present in the fetal gut, whereas NKp46 ${ }^{+}$ILC3s are largely absent (10), only expanding after birth in response to diet-derived AHR ligands (12-14) and signals from the maternal microbiota (36). Similarly, ILC2s seed the mouse lungs within the first 2 weeks of life (37). The differential tissue distribution of ILCs is likely related to their migratory behavior, e.g., due to temporal seeding of tissues during embryogenesis $(10,38)$ and due to organ-specific expression of integrins and chemokine receptors on ILCs (Figures 1-3).

Parabiosis studies in mice established the concept that, in contrast to NK cells, ILCs in both lymphoid and non-lymphoid tissues are largely tissue-resident cells (39). This implies that, similar to tissue macrophages, ILCs are maintained within tissues by local self-renewal. However, recent studies have challenged this concept with the discovery of circulating CD117 ${ }^{+}$ILC precursors (ILCPs) in humans (40) and the observation that inflammatory ILC2s in the mouse can migrate from the intestine to the lung during helminth infection (41). Circulating ILCs might therefore constitute mobile a pool of cells that can be activated and recruited to inflamed tissue on demand in order to support host defense carried out by tissue-resident ILCs (Figures 1, 3). Apart from ILCPs, human blood also contains ILC2s (27), but no mature ILC1s and ILC3s (40). In addition to more abundant NK cells, circulating putative ILCPs and mature ILCs, mainly ILC1s, are also found in mice $(42,43)$.

Interestingly, ILCs occupying vascular vs. tissue compartments seem to have distinct functions. A recent study demonstrated that NK cells circulating between blood and peripheral tissues have effector function, whereas NK cells trafficking to lymph nodes are long-lived and proliferative (44). This different migratory and functional behavior has been associated with the differential expression of transcription factors (44).

\section{TISSUE NICHES AND ILC FUNCTION}

Like other immune cells, ILCs occupy distinct niches within tissue, which is important for their function and likely regulates their homeostasis. For example, in the intestine, ILCs reside in three main anatomical compartments: (i) LTi-like ILC3s are clustered in lymphoid tissues, such as cryptopatches and isolated lymphoid follicles $(45,46)$; (ii) NK cells/ILC1s, ILC2s, NKp46 ${ }^{+}$ILC3s are dispersed in the lamina propria (47-49); (iii) Intraepithelial ILC1s are located within the epithelium (30, 50). This anatomical compartmentalization corresponds to the diversity of ILC function in the intestine (Figure 2). For example, LTi-like ILC3s in Peyer's Patches and isolated lymphoid follicles interact with B cells to stimulate IgA production $(51,52)$, which promotes host commensalism with the local microbiota (53). Furthermore, lymphoid tissue-resident commensal bacteria are contained by IL-22-producing ILC3s (54). In addition, ILC3s in cryptopatches are in close proximity to the cypts, where intestinal stem cells reside. Accordingly, IL-22 production by ILC3s has been shown to maintain crypt stem cells after tissue damage (5557). In contrast, NKp46 ${ }^{+}$ILC3s are mostly resident in the small 


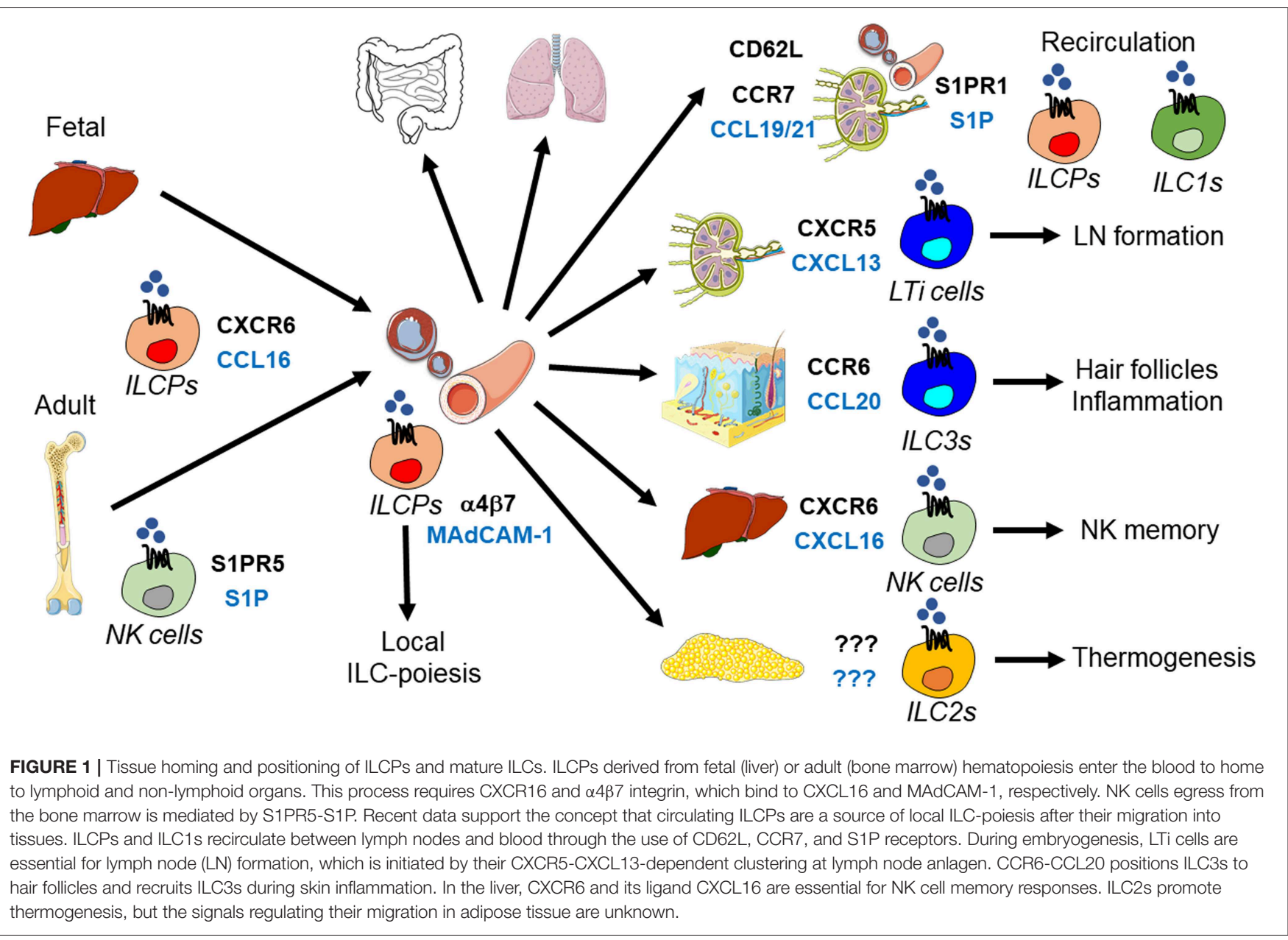

intestinal villi, located close to the epithelium, where they mediate host defense against pathogens (58). Interestingly, $\mathrm{NKp} 46^{+}$ ILC3s seem to produce IL-22 mainly in response to pathogeninduced IL-23 secretion by myeloid cells, whereas lymphoid tissue-resident LTi-like ILC3s produce IL-22 constitutively in a microbiota-dependent manner (59). Finally, IFN $\gamma$-secreting ILC1s within the intraepithelial compartment are involved in colitis (50).

Although intestinal ILC3s are tissue-resident (39), they are not completely sessile cells. For example, in the steady state, there is a constant influx and egress of ILC3s to and from cryptopatches and there is increased ILC3 mobilization from cryptopatches during inflammation $(21,60)$. The significance of steady-state ILC3 migration in and out of cryptopatches is unknown, but could potentially serve the purpose of sampling or sensing cues from the environment (such as crypt material) to respond to perturbations of the intestinal stem cell compartment. Accordingly, it has been suggested that cryptopatches act as a platform to rapidly amplify ILC-mediated immune responses, not only through cytokine production, but also through ILC movement into surrounding tissue (60).

Interestingly, occupancy of tissues niches by ILCs is regulated by quorum sensing-like mechanisms. Thus, it has recently been shown that receptor activator of nuclear factor kappa
B (RANK)-RANK ligand (RANKL) interactions adjust the numbers of mouse CCR6 ${ }^{+}$LTi-like ILC3s to the size of the niche, likely within cryptopatches (61). Therefore, regardless of their outer environment, clustering of CCR6 $6^{+}$ILC3s allows them to keep one another in check. This mechanism likely operates also in human tonsil, where CCR6 ${ }^{+}$ILC3s express both RANK and RANKL (61).

In many tissue niches, ILCs have an intimate relationship with non-hematopoietic cells, such as stromal cells. For example, an ILC3-stromal cell niche in secondary lymphoid organs has been reported in both mice and humans (62). Moreover, ILC2s occupy a distinct perivascular localization close to stromal cells in the lung $(63,64)$. In this specific niche, adventitial stromal cells promote ILC2 homeostasis in steady-state and in response to helminth infection through the production of IL-33 and thymic stromal lymphopoietin (TSLP) (64). In turn, ILC2-derived IL-13 supports the expansion and IL-33 production by adventitial stromal cells (64). The close proximity of lung ILC2s to blood vessels has been proposed to allow efficient recruitment of eosinophils from the blood (63), further underscoring the importance of ILC intra-tissue localization (Figure 3). Furthermore, ILC2s are strategically positioned within the airways, near airway branch points (65), where inhaled particles are thought to accumulate. This puts ILC2s in close 


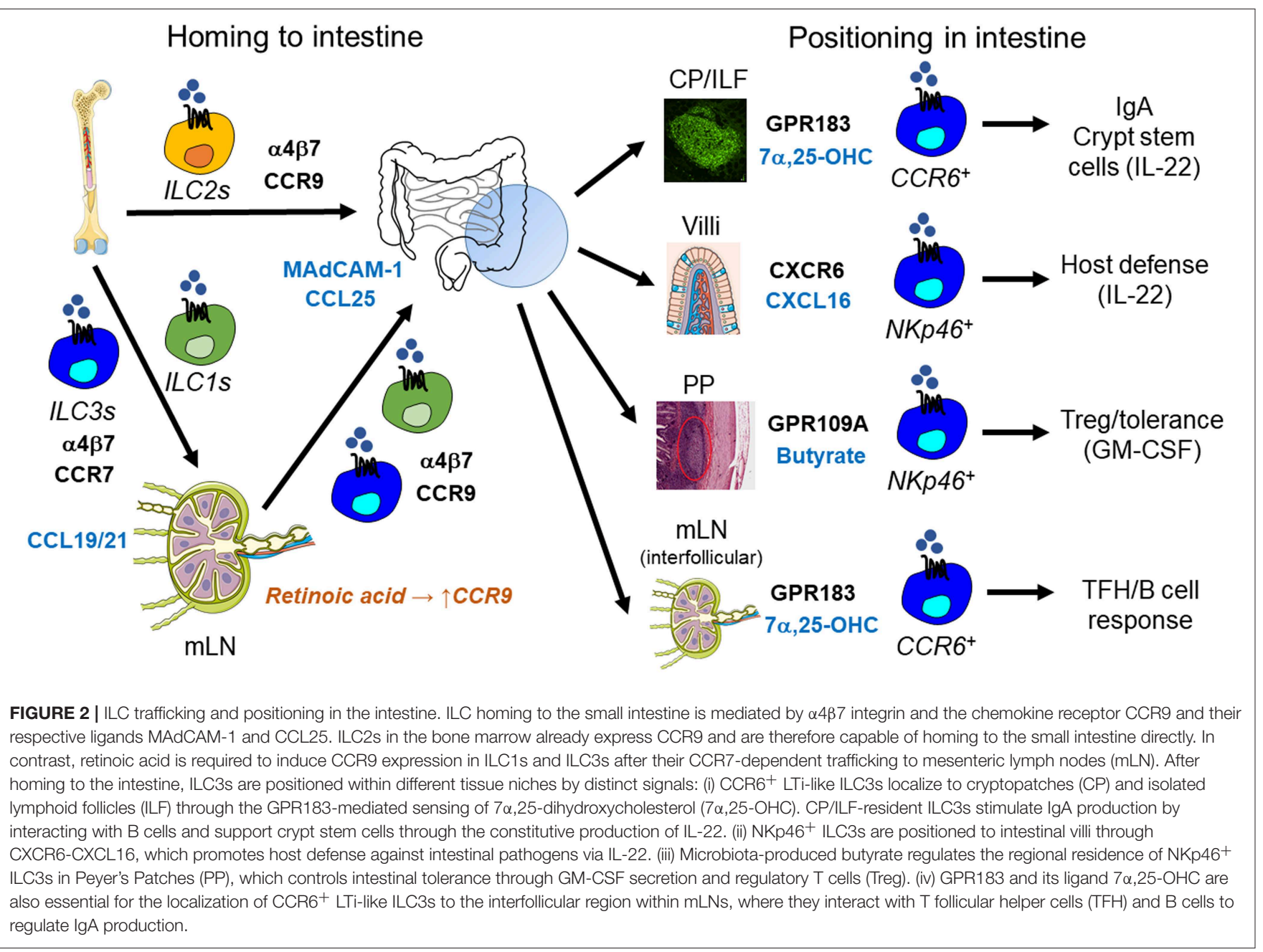

contact with neuroendocrine cells that activate ILC2s through the release of calcitonin gene-related peptide (65). ILC-neuron interactions also occur in intestinal cryptopatches (66) and accordingly neuronal circuits have been shown to regulate ILC function in different contexts (66-71).

Furthermore, there is the emerging concept that different tissue microenvironments specify ILC function, as has been shown for ILC2s (72). Local tissue niches might also regulate ILC function through stimulating ILC plasticity. In vitro, ILC plasticity occurs through the exposure to polarizing cytokines, such as IL-1 $\beta$ and IL-12, which induces the conversion of ILC2s and ILC3s into ILC1s $(35,73-76)$. However, it is unclear where these factors are produced in vivo and where ILC trans-differentiation occurs within tissue. One possibility is that migratory signals induced by inflammation guide ILCs to specific niches, where they are exposed to polarizing cytokines. Alternatively, the polarizing cytokines might be produced within the same niche in response to inflammatory stimuli.

Overall, the signals and migratory receptors regulating the co-localization and interaction of ILCs with stromal cells and other immune cells, such as $\mathrm{T}$ cells, are largely unknown. Subsets of ILCs interact with $\mathrm{T}$ cells through the expression of major histocompatibility complex (MHC) class II, CD1d, OX40 ligand (OX40L), and CD30 ligand (CD30L) (77). In the intestine, MHC class $\mathrm{II}^{+}$ILC3s suppress $\mathrm{CD} 4 \mathrm{~T}$ cell responses against the local microbiota $(78,79)$, whereas the interaction of MHC class $\mathrm{II}^{+}$ ILC2s with CD4 $\mathrm{T}$ cells promotes type 2 immunity in the lung (80). Moreover, OX40L-expressing ILC2s stimulate Th2 and regulatory $\mathrm{T}$ cell (Treg) responses in lung and adipose tissue (81). Interestingly, adult LTi-like ILC3s constitutively express costimulatory ligands (OX40L, CD30L), whereas fetal LTi cells do not (82).

Another interesting area for future investigation is the occupation of tissue niches by ILCs and their adaptive counterparts, i.e., $\mathrm{T}$ cells. This is particularly relevant since both ILCs and T cells largely dependent on the same factors $\left(\gamma_{c}\right.$ cytokines) for their homeostasis and expansion, therefore likely competing with each other. Accordingly, intestinal ILC2s and ILC3s expand in T cell-deficient mice, e.g., in mice lacking Rag genes (16), most likely due to increased availability of IL-2 and IL-7. This notion is supported by the finding that intestinal ILC3s outcompete T cells for IL-2 (79) and that IL-7 consumption by 


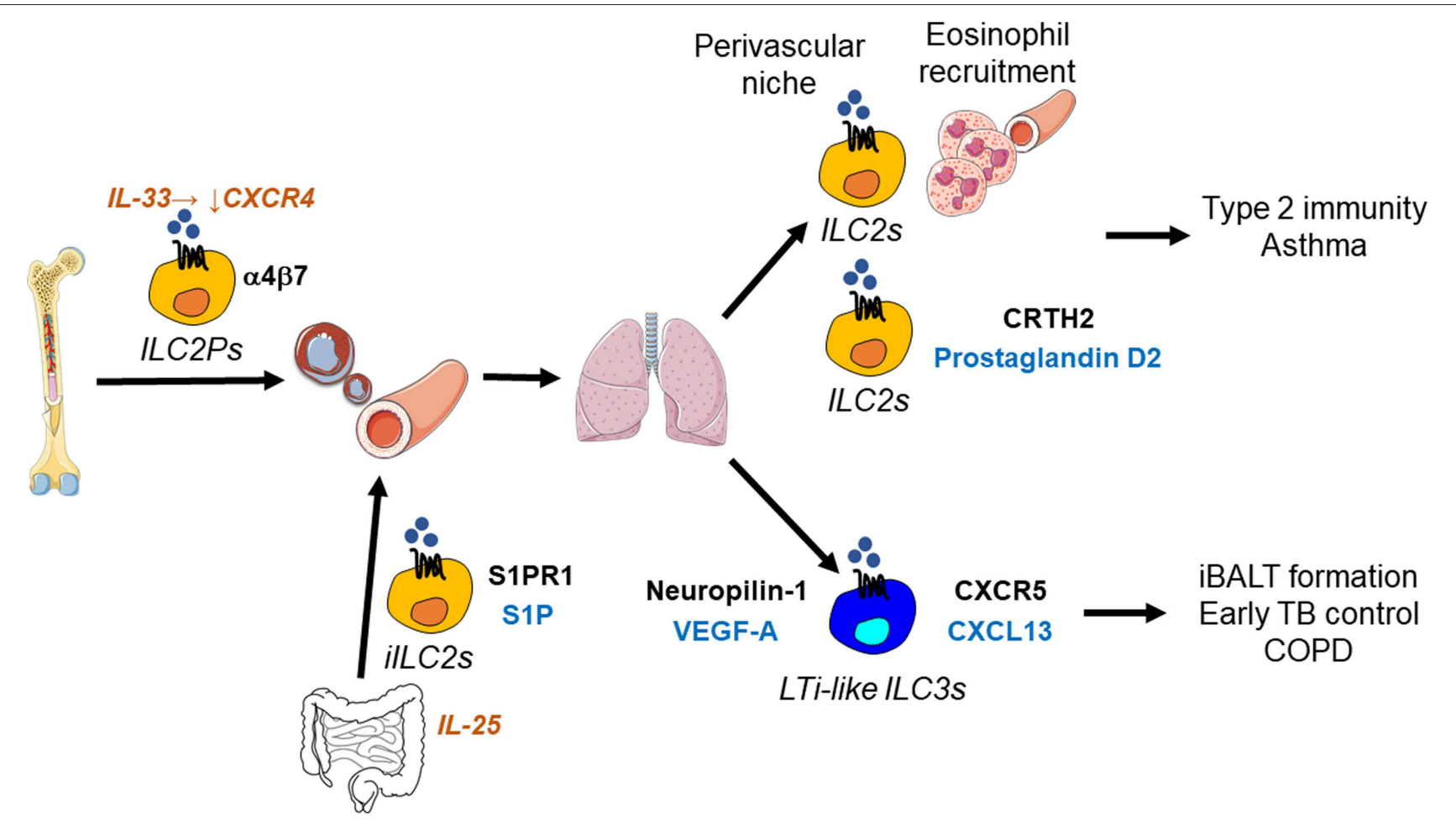

FIGURE 3 | ILC migration in the lung. Suppression of CXCR4 by IL-33 enables ILC2Ps to egress from the bone marrow and home to the lung, where they occupy a perivascular niche. This strategic localization likely allows ILC2-mediated recruitment of eosinophils from the circulation into the lung. In addition, prostaglandin D2 stimulates ILC2 migration in the lung through the interaction with its receptor CRTH2 on ILC2s. ILC2s thereby promote type 2 barrier immunity, but also allergic inflammation as in asthma. During helminth infection, IL-25-responsive inflammatory ILC2s (ilLC2s) are capable of trafficking from the intestine to the lung, where they support anti-helminth immunity. This inter-organ trafficking requires S1PR1-S1P. LTi-like ILC3s migrate in the lung using CXCR5-CXCL13 and likely neuropilin-1-VEGF-A. LTi-like ILC3s mediate the formation of inducible bronchus-associated lymphoid tissue (iBALT), which is essential for the early control of tuberculosis (TB) in the lung, but may also be involved in inflammatory responses occurring in chronic obstructive pulmonary disease (COPD).

ILCs regulates the amount of IL-7 that is available to T cells (83). Finally, it has been suggested that IL-2 produced by proliferating T cells maintains LTi-like ILC3s in lymphoid structures (77), in accordance with the observation that mesenteric lymph noderesident ILC3s are reduced in T cell-deficient mice (84). However, in many tissues it has not been thoroughly investigated whether ILCs and T cells occupy distinct or overlapping niches.

\section{ILC TRAFFICKING TO TISSUES}

\section{Trafficking Receptors on ILCs}

Mature ILCs are largely tissue-resident cells (39), yet the signals that control the migration of ILCPs and mature ILCs into tissues during embryogenesis, adult life, and inflammation are still incompletely understood. Similar to T lymphocytes, ILC trafficking to tissues is regulated by integrins and chemokine receptors (Table 1) that are often expressed in an ILC subsetspecific manner with similar chemokine receptor expression as the corresponding $\mathrm{T}$ helper subsets (32).

For example, LTi-like ILC3s express CCR6 and CXCR5 $(10,11)$, both transcriptional targets of $\operatorname{ROR} \gamma \mathrm{t}$, which are also preferentially expressed on Th17 cells (CCR6) and T follicular helper cells (CXCR5). CCR6 and CXCR5 are already expressed on ILC3Ps that migrate to peripheral tissues from the fetal liver and adult bone marrow (9). In contrast, NKp46 ${ }^{+}$ILC3s express CXCR6 (29, 92), the receptor for CXCL16, which mediates their localization to the lamina propria (58). ILC1s also express CXCR6 (92). Furthermore, CXCR6 promotes the homing of NK cells to the liver, which is important for NK cell memory (93). Lymphoid tissue-resident human ILC3s with LTi activity, as well as murine fetal $\mathrm{CD} 4^{+}$LTi cells, not only express CCR6 and CXCR5, but also Neuropilin-1, which mediates their migration toward vascular endothelial growth factor-A (VEGFA) (99). Finally, distinct subsets of intestinal ILC3s express CD49a (integrin $\alpha 1$ ) (86). Moreover, similar to Th2 cells, both mouse and human ILC2s express CCR4 $(27,29,100)$ and other skin-homing receptors, such as cutaneous leukocyte-associated antigen (CLA) and CCR10 that bind to endothelial cell-leukocyte adhesion molecule 1 (ELAM-1) and CCL27/CCL28, respectively (32). It has been reported that ILC2s in broncho-alveolar lavage fluid highly express CCR4 (and CCR7) after IL-33 administration (101), suggesting a role for CCR4 and its ligands CCL17 and CCL22 in ILC2 migration following activation, although this prediction requires experimental validation. CCR8 is another chemokine receptor that shows shared expression in ILC2s and Th2 cells (29), which may mediate ILC homing to the skin 
TABLE 1 | Receptors involved in ILC migration.

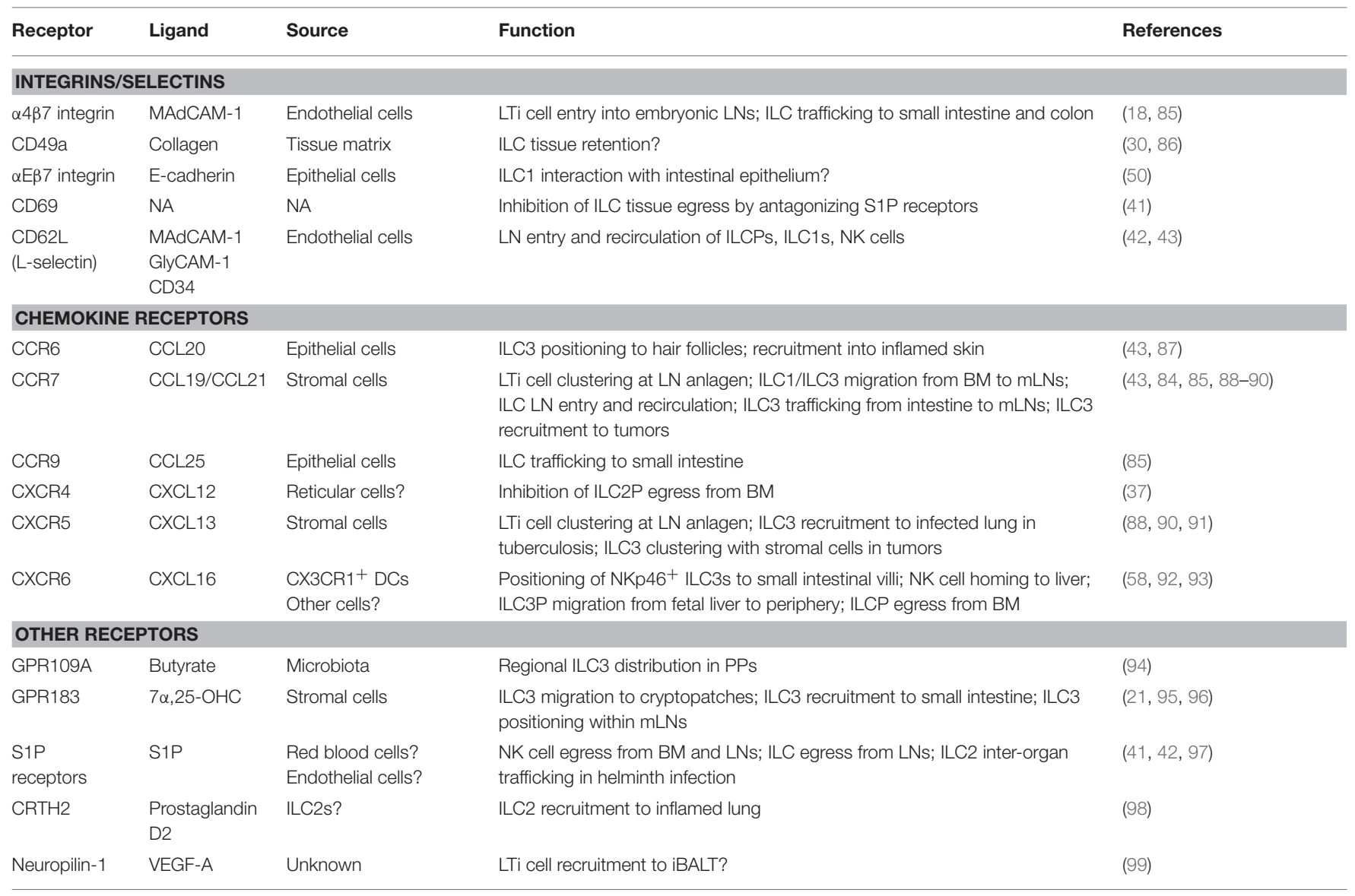

BM, bone marrow; iBALT, inducible bronchus-associated tissue; $L N$, lymph node; $m L N$, mesenteric lymph node; PP, Peyer's Patch.

in response to CCL1. In contrast, ILC1s and NK cells share preferential expression of CXCR3, the receptor for CXCL9, CXCL10, and CXCL11, with Th1 cells (102). Furthermore, expression of CD49a and CD49d (integrin $\alpha 4$ ) can be used to distinguish subpopulations of intestinal ILC1s (86). NK cells also express integrins, such as CD49a and CD49b (integrin $\alpha 2$ ) (32). In addition to subset-specific expression, migratory receptors are also expressed in a tissue-specific manner within the same ILC subset. For example, ILC2s in adipose tissue have higher expression of Itgae, Ccr6, and Cxcr4 than ILC2s from other tissues (72).

\section{Seeding of Tissues With ILCs During Development}

In mice, ILCs derived from fetal liver hematopoiesis are among the first lymphocytes to seed barrier tissues, such as the intestine before birth $(10,12,38)$ (Figure 1). This tissue seeding prepares the host for the colonization of the intestine with the microbiota and the intake of food-derived antigens. Moreover, LTi cells populate organs early to promote the formation of lymphoid tissues (22). ILCPs express $\alpha 4 \beta 7$ integrin, whose ligand MAdCAM-1 is widely expressed in the fetus, thereby allowing ILCP migration to a variety of tissues (32). The entry of LTi cells into embryonic lymph nodes is also dependent on $\alpha 4 \beta 7$ integrin (103). Furthermore, the interaction of CXCL13, induced by retinoic acid in mesenchymal organizer cells, with CXCR5 on LTi cells is required for the clustering of LTi cells at embryonic lymph node anlagen and lymph node development, with a minor contribution of CCL21 and its receptor CCR7 (88). Further work showed that the amount of maternal retinoic acid regulates the number of LTi cells and therefore the size of lymph nodes, which determines anti-viral immunity later in life (15). Before birth, LTi cells also cluster at embryonic anlagen to promote the formation of Peyer's Patches, which is dependent on expression of RET, a tyrosine kinase receptor for neurotrophic factors, on LTi cells (104). In addition, arginase 1-expressing ILCPs accumulate at Peyer's Patch anlagen, where they can give rise to ILC1s, ILC2s, and ILC3s in the fetal intestine (38). This ILCP clustering occurs in a CXCR5- and CCR7-independent manner, since, in contrast to LTi cells, these Arginase $1^{+}$ILCPs do not express CXCR5 and CCR7 (38). In contrast to LTi cells, Arginase $1^{+}$ILCPs also lack lymphotoxin expression and are therefore dispensable for Peyer's Patch organogenesis (38). Finally, fetal $\alpha 4 \beta 7^{+} \mathrm{CXCR}^{+} \mathrm{CCR}^{+}{ }^{+} \mathrm{CXCR}^{+}$ILC3Ps migrate from fetal liver to lymphoid organs and intestine $(9,105)$ in a CXCR6-dependent manner (92). ILCs are also found in human fetal tissues (27), suggesting that early colonization of tissues with ILCs is conserved between mice and humans. 
Overall, embryonic tissue seeding of ILCPs is reminiscent of the colonization of tissues with embryonically-derived macrophages $(106,107)$. In contrast to organs that are seeded before birth (e.g., the intestine), other organs, such as the lung and spleen, are colonized with ILCs after birth. Later, during adult life, there is likely a second wave of ILCPs from bone marrow (or other tissues) that enter the circulation and gain access to tissues to contribute to the ILC pool found in peripheral organs. Again, this might be in analogy to macrophages, where, in the adult organism, circulating monocytes enter tissues and, under specific conditions, can differentiate into tissue-resident macrophages.

\section{ILC Trafficking to Lymph Nodes}

In adult mice, ILCs use similar mechanisms as naïve $\mathrm{T}$ cells for lymph node entry (Figure 1). For example, like NK cells, ILCs (especially ILCPs and ILC1s) enter peripheral lymph nodes using CD62L (L-selectin) and CCR7 $(42,43)$. In addition, LTi-like ILC3s are capable of trafficking from the intestine to draining mesenteric lymph nodes in a CCR7-dependent manner (84). In contrast, ILC1s, ILC2s, and NKp46 ${ }^{+}$ILC3s do not migrate along this route. Accordingly, LTi-like ILC3s migrate toward the CCR7 ligand CCL21 in vitro, whereas ILC2s are unable to do so (84). Finally, the trafficking of LTi-like ILC3s to the spleen is not critically dependent on CCR7 (84).

\section{ILC Trafficking to the Intestine}

Tissue-specific signals from the local microenvironment likely play an important role in the trafficking of ILCs to the intestine, including cues from the microbiota, which might be particularly important for intestinal ILC3s $(36,86)$. In addition, metabolic cues are essential as has been demonstrated in a few studies so far (Figure 2). For example, it has been shown that the preferential homing of ILCs to the small intestine is controlled by dietderived nutrients. ILCPs and mature ILC subsets express $\alpha 4 \beta 7$ integrin, CCR7, and CCR9 to varying degrees $(85,92)$ and, similar to T lymphocytes, ILC1, and ILC3 trafficking to the small and large intestine requires $\alpha 4 \beta 7$ integrin (85) that binds to MAdCAM-1, abundantly expressed on endothelial cells in the intestine. Furthermore, the Vitamin A metabolite retinoic acid is essential for the homing of ILC1s and ILC3s, but not ILC2s, to the small intestine (85). Specifically, it was found that ILC1s and ILC3s migrate from the bone marrow to mesenteric lymph nodes in a CCR7-dependent manner, where retinoic acid induces expression of $\alpha 4 \beta 7$ integrin and CCR9 (85), whose ligand CCL25 is abundant in the small intestine. In contrast, CCR9 expression is acquired by $\alpha 4 \beta 7^{+}$ILC2Ps already in the bone marrow and therefore retinoic acid-independent $(85,100)$. This feature likely links the nutrient status of the host to the type of local immune response through the preferential migration of specific ILC subsets to the small intestine. This concept is consistent with the observation that lack of Vitamin A, as it occurs in malnutrition, causes a reduction of ILC3s and impaired protection against bacterial pathogens in the intestine, whereas ILC2s and antihelminth responses are increased (16). This switch to type 2 barrier immunity likely ensures continued commensalism with evolutionary partners (helminths, commensal bacteria) in the small intestine during nutrient deficiency. In contrast, the homing of ILC 3 s to the colon requires $\alpha 4 \beta 7$ integrin, but not
CCR9, and is therefore independent of retinoic acid (85). It has not been explored whether other chemotactic receptors used by T cells, such as GPR15 (108), enable ILC homing to the colon.

\section{Circulating ILCPs}

ILCPs are present within tissues, such as the intestine and other organs, including blood, in mice and humans (9, 38, 40, 42, 109, 110). Despite the presence of ILCPs in both peripheral blood and tissues, parabiosis studies in mice indicate that ILCs other than NK cells in both lymphoid and non-lymphoid tissues are mainly tissue-resident (39). Subsequently, this concept has been challenged by the finding that human $\mathrm{CD} 34^{-} \mathrm{CD} 117^{+}$ILCPs are present not only in blood, but also in a variety of lymphoid and non-lymphoid tissues (40), demonstrating that these ILCPs can leave the circulation and migrate into tissues. Furthermore, these circulating human $\mathrm{CD} 117^{+}$ILCPs can be considered the equivalent of naïve $\mathrm{T}$ cells since they lack immediate effector function, but have the ability to differentiate into mature ILC1s, ILC2s, and ILC3s in vitro and upon adoptive transfer into mice. ILCPs were therefore proposed to serve as cellular substrates for local "on-demand" ILC-poiesis within tissue (111). Further studies are needed to clarify potential species-specific differences in ILC migration/tissue residency between humans and mice and to establish to what extent mature ILCs in tissues are replenished by circulating ILCPs.

Progenitors upstream of human $\mathrm{CD}^{-} 4^{-} \mathrm{CD} 117^{+}$ILCPs express the adhesion/homing receptor CD34 and are found in a variety of tissues, but not in blood (111). It is plausible that loss of CD34 expression on CD34 ${ }^{+}$ILCPs triggers the entry of $\mathrm{CD} 34^{-} \mathrm{CD} 117^{+}$ILCPs into the circulation (111). Furthermore, IL-1 $\beta$ (in combination with IL-2 and IL-7) acts as a growth factor for $\mathrm{CD} 117^{+}$ILCPs in vitro (40) and it has been suggested that production of IL- $1 \beta$ induced by disruption of tissue homeostasis promotes the migration of ILCPs from blood into tissue (111). However, as a cytokine, IL-1 $\beta$ lacks direct chemotactic activity and therefore other, yet unknown, chemotactic guidance cues and their corresponding receptors must be involved.

\section{ILCP Egress From Bone Marrow}

In mice, ILCPs and ILC2Ps, unlike common lymphoid progenitors, express the chemokine receptor CXCR6 and their egress from the bone marrow is partially dependent on CXCR6, thereby regulating ILCP entry into the circulation (92). In contrast, adult ILC3Ps migrate from the bone marrow to the periphery in a CXCR6-independent manner (9). Furthermore, a recent study demonstrated that IL-33 signaling is required for the egress of ILC2Ps from the bone marrow during the perinatal period by downregulating CXCR4 expression (37). Finally, the bioactive lipid sphingosine-1 phosphate (S1P) promotes lymphocyte egress from several organs (112) and S1P receptor 5 (S1PR5) is essential for the bone marrow egress of NK cells (97). However, it has not been investigated whether S1P receptors also regulate the egress of ILCPs from bone marrow.

\section{ILC Recirculation}

Both mouse and human ILCPs in the blood express CD62L, which promotes lymph node entry of ILCPs, whereas lymph node exit requires S1P receptors (42). The later possibility is further 
supported by the finding that treatment with the S1P agonist FTY720, which disrupts S1P gradients and results in S1P receptor internalization from the cell surface (112), causes ILC-penia, while increasing the number of ILCs in lymph nodes (113). These studies are consistent with the concept that, similar to naïve $\mathrm{T}$ cells, ILCPs and some mature ILCs have the ability to re-circulate between blood and lymphoid organs (Figure 1). This notion is further supported by a recent study in mice, demonstrating that ILC1s (similar to NK cells) recirculate between blood and lymph nodes in a CD62L- and CCR7-dependent manner, whereas ILC3s in lymph nodes are mainly tissue-resident (43). Furthermore, among human ILCs, NKp44- ILC3s, likely representing ILCPs (40), have higher expression of genes encoding surface receptors involved in lymphocyte recirculation (CD62L, CCR7, S1PR1) than NKp44 $4^{+}$ILC3s (114). Finally, compared to their circulating counterparts, human lymphoid tissue-resident ILC3s express CXCR5 and CCR7, known to regulate positioning within lymphoid organs (114).

\section{Tissue Retention of ILCs}

Finally, less is known about the factors that retain ILCs within tissues once they are recruited. This likely involves the same receptors that are required for the tissue retention of $\mathrm{T}$ lymphocytes (115) (Table 1). For example, intestinal and skin ILCs express CD69 (41, 48, 92), which antagonizes the egress receptor S1PR1 (116). In addition, ILC2s from human tissues express the collagen-binding integrin CD49a (30) that has been shown to promote $\mathrm{T}$ cell retention in tissues. Populations of mouse ILC1s and ILC3s also express CD49a (86) as do human intraepithelial ILC1s in the intestine (50). In addition, the latter subset expresses CD103 ( $\alpha$ E integrin) (50), which together with $\beta 7$ integrin binds to E-cadherin on epithelial cells. CD103 ${ }^{+}$ILC2s have also been identified in mouse skin (117). Further studies (such as genetic ablation in mice) are required to demonstrate a direct role for specific receptors in the tissue retention of ILCs.

\section{ILC POSITIONING WITHIN TISSUE}

ILCs occupy strategic positions within tissues to perform their organ-specific functions. Proper ILC positioning within tissue is also critical for the spatial compartmentalization of tissue immunity. For example, as discussed above, ILCs inhabit tissuespecific niches, which facilitates the interaction with other immune cells as well as with non-hematopoietic cells. However, there is very limited knowledge regarding the signals and receptors that direct ILCs to local tissue niches. Recent work elucidated how metabolic signals ensure that ILCs are properly positioned in the intestine to carry out their function. We found that intestinal ILC3s lacking the G protein-coupled receptor GPR183 (also known as EBI2) exhibit aberrant localization (21). GPR183 recognizes hydroxylated metabolites of cholesterol, socalled oxysterols, with $7 \alpha, 25$-dihydroxycholesterol as the main GPR183 ligand $(118,119)$. We demonstrated that oxysterols sensed through the receptor GPR183 function as guidance cues to position ILC3s within intestinal cryptopatches, which is critical for lymphoid tissue formation in the colon (21) (Figure 4). Similar findings have been subsequently reported by two other

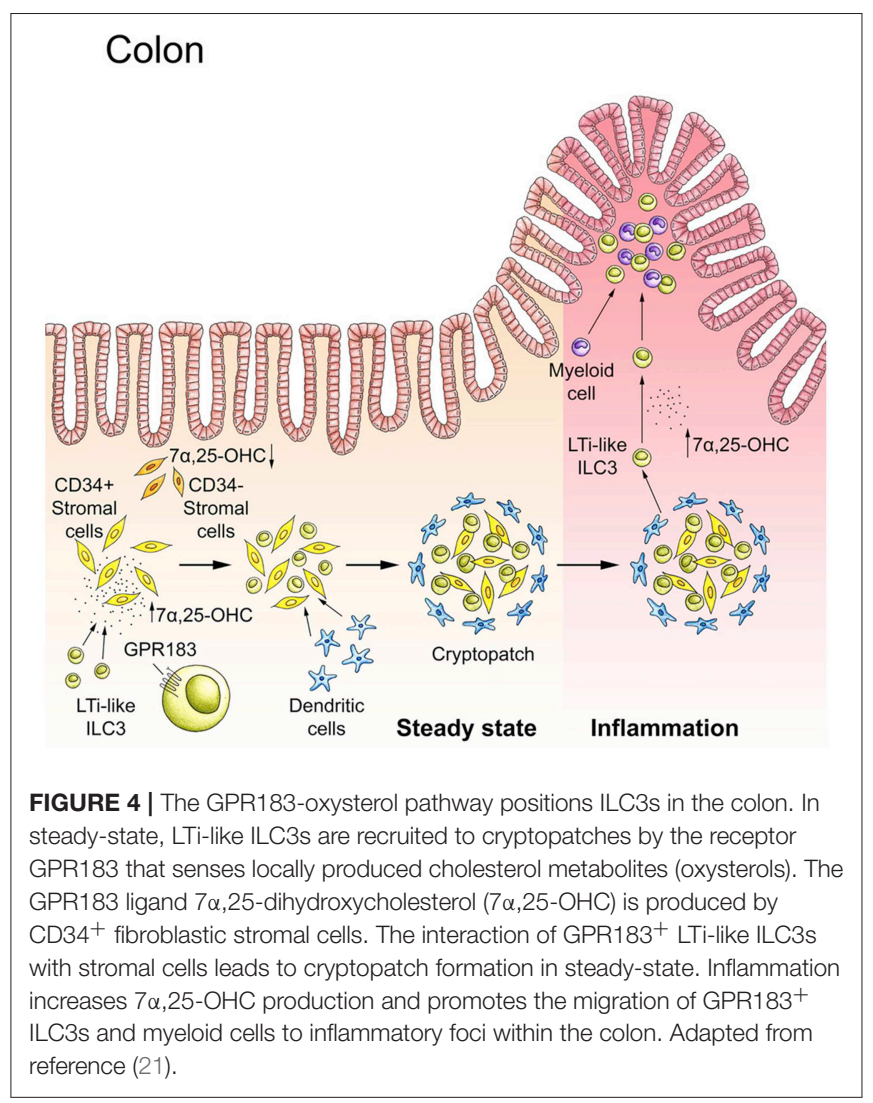

labs $(95,120)$. Chu et al. found that GPR183 also regulates ILC3 recruitment to the small intestine (but not to the colon), possibly through promoting $\alpha 4 \beta 7$ integrin surface expression on ILC3s (95). We further showed that oxysterols are produced by specialized stromal cells located within cryptopatches/isolated lymphoid follicles (21). The intriguing possibility that dietary cholesterol in breast milk is a source of oxysterols required for post-natal lymphoid organogenesis in the colon remains to be explored (119).

This complements previous work showing that CXCL16 produced by $\mathrm{CX} 3 \mathrm{CR} 1^{+}$dendritic cells guides the positioning of $\mathrm{CXCR}^{+}{ }^{-} \mathrm{NKp}_{4} 6^{+}$ILC3s to the villi of the small intestine, where they contribute to epithelial defense through the production of IL-22 (58). Notably, the chemokine receptors CCR6 and CXCR5 (and their respective ligands CCL20 and CXCL13), although specifically expressed by LTi-like ILC3s, are not required for ILC3 migration to cryptopatches, neither in the small nor large intestine $(121,122)$. However, it has recently been reported that skin ILC3s are positioned within hair follicles in a CCR6dependent manner (87). In mesenteric lymph nodes, ILC3s are found in a specific anatomical location, the interfollicular region (84), and GPR183 also promotes the proper positioning of ILC3s to this region, whereas CCR6 and CXCR5 are dispensable $(95,96)$.

Apart from NK cells that largely lack GPR183, ILC subsets other than LTi-like ILC3s also express GPR183 to varying degrees (21). However, the specific functions of GPR183 in other ILC subsets is unknown. Overall, our recent work and that of others 
indicates an important role for local cholesterol metabolites in directing ILC migration.

Other lipids, such as leukotrienes and prostaglandins, are likely relevant for the intra-tissue localization of ILCs (Figure 3). For example, human ILC2s are phenotypically defined by the expression of CRTH2 (27), the prostaglandin D2 receptor, and prostaglandin D2 induces the chemotaxis of ILC2s in vitro (123). Accordingly, CRTH2 mediates accumulation of mouse ILC2s in the inflamed lung (98). Moreover, human ILC2s found in asthma are responsive to the lipid mediators prostaglandin D2 and lipoxin A4 (124). As mentioned above, amino acid derivatives, such as a tryptophan metabolites, can regulate ILC homeostasis through AHR. However, it is currently unknown whether amino acid-derived molecules can also act as chemotactic cues, guiding ILC positioning.

Apart from host-derived signals, the gut microbiota also likely regulates ILC migration and positioning through the local production of metabolites. For example, lymphoid-tissue resident commensal bacteria promote ILC3 localization to mesenteric lymph nodes and Peyer's Patches (125). Furthermore, the short-chain fatty acid butyrate controls the compartmentalization of ILC3s in Peyer's Patches (94). Specifically, it has been shown that butyrate, sensed through the receptor GPR109A on ILC3s, is more abundant in ileal than jejunal Peyer's Patches, thereby inhibiting the residence of $\mathrm{CCR}^{-} \mathrm{NKp}^{+} 6^{+}$(and $\mathrm{CCR}^{+}{ }^{+} \mathrm{NKp} 46^{-}$) ILC3s in ileal Peyer's Patches (94).

Overall, more metabolic signals remain to be identified that promote proper ILC localization in healthy and inflamed tissue. The use of lipid metabolites, rather than the exclusive use of genome-encoded proteins (chemokines), as guidance cues for ILCs within tissue might be advantageous for the host. Lipid metabolites can be rapidly produced and inactivated through enzymatic conversion, as exemplified by the GPR183 ligand $7 \alpha, 25$-dihydroxycholesterol since its synthesis from cholesterol is controlled by two enzymes, cholesterol 25-hydroxylase $(\mathrm{CH} 25 \mathrm{H})$ and $7 \alpha$-hydroxylase (CYP7B1); and it can be further metabolized into bile acid precursors that lack chemotactic activity by the enzyme $3 \beta$-hydroxysteroid dehydrogenase type 7 (HSD3B7) (118). This allows tight regulation of $7 \alpha, 25$-dihydroxycholesterol abundance within tissue. Furthermore, lipid metabolites likely easily diffuse within tissue, thereby facilitating the generation of precise local chemotactic gradients. Finally, from the same precursor molecule, two bioactive metabolites with distinct functions can be generated: 25-hydroxycholesterol generated by $\mathrm{CH} 25 \mathrm{H}$ from cholesterol has anti-viral and anti-inflammatory activity, whereas $7 \alpha, 25$-dihydroxycholesterol synthesized from 25-hydroxycholesterol by CYP7B1 regulates immune cell migration through GPR183 (118). This feature likely allows coordinated regulation of tissue-resident immune function by lipid metabolites.

\section{ILC MIGRATION DURING INFLAMMATION}

During infection and other tissue insults, ILCs must migrate to local sites of inflammation within tissue. For example,
Neuropilin- ${ }^{+}$human LTi cells are present in inducible bronchus-associated lymphoid tissue (BBALT) in the inflamed lung in chronic obstructive pulmonary disease (COPD) (99). A recent study showed that, in Mycobacterium tuberculosis infection, ILC3s are recruited via the CXCL13-CXCR5 axis to the lung, thereby mediating the formation of iBALT associated with granulomas, which contributes to early control of infection together with the production of IL-17 and IL-22 (91). In addition, IL-17-producing ILC3s are present in the alveolar space in asthma patients (126). Similarly, ILC2s are increased in the broncho-alveolar lavage fluid of humans with idiopathic pulmonary fibrosis (127). Furthermore, it has recently been shown that ILCs are recruited into the inflamed skin in a CCR6dependent manner (43). Finally, the accumulation of LTi-like ILC3s in mesenteric lymph nodes after helminth infection is dependent on CCR7-mediated trafficking (84).

The GPR183-oxysterol pathway also plays an important role in controlling ILC migration in inflamed tissue (119). Mobilization of ILC3s from cryptopatches into the surrounding tissue occurs during intestinal inflammation (60). We showed that the recruitment of ILC3s (and myeloid cells) to inflammatory foci in the colon is dependent on GPR183 (21) (Figure 4). It is reasonable to assume that increased oxysterol synthesis induced by tissue injury conveys perturbation of tissue homeostasis to the immune system, initiating ILC movement and the inflammatory response (119). It is currently unknown whether other metabolites produced in inflamed tissue regulate ILC migration and localization.

An important feature of ILCs is their ability to contribute to the repair of tissues damaged by infection, inflammation, and irradiation, which is likely dependent on their local migration and accumulation within damaged tissues. For example, LTi-like ILC3s restore lymphoid tissue architecture after viral infection (128), promote thymic regeneration after irradiation (129), and protect the intestine from graft vs. host disease-induced damage after hematopoietic stem cell transplantation (55). Similarly, ILC2s alleviate virus-induced damage to the lung (33).

Moreover, a recent study established the new concept of ILC inter-organ trafficking during inflammation. Specifically, it was shown that inflammatory IL-25-responsive ILC2s can migrate from the intestine to the lung during helminth infection to support host defense (41). The exit of ILC2s from the intestine into the blood via the lymphatic system was mediated by S1P (41), the critical factor regulating lymphocyte egress from tissues (112). CD69, expressed on tissue-resident ILCs, antagonizes S1PR1 through downmodulation of S1PR1 from the cell surface (116). In contrast, inflammatory ILC2s are $\mathrm{CD}^{-} 9^{-}$, allowing S1PR1-dependent egress into the circulation (41). A previous study in mice had found that intestinal NK cells, ILC1s, and ILC3s are CD69 $9^{\text {hi }}$, whereas ILC2s are CD69 lo, supporting the concept that intestinal ILC2s might be "less tissue-resident" than other intestinal ILC subsets (92). Finally, it has been suggested that signals from the local microbiota promote S1P receptor expression on ILC2s, thereby allowing them to exit the intestine (130).

It remains to be tested whether inter-organ trafficking of ILCs also occurs between other organs. In this context, it is 
relevant that in various inflammatory conditions activated ILCs are found in peripheral blood. For example, human NKp $44^{+}$ ILC3s expressing homing receptors for skin and intestine appear in the circulation after conditioning for hematopoietic stem cell transplantation (131). Similarly, circulating ILC2s are increased in humans with asthma (132). These observations suggests that inter-organ trafficking might also occur in humans after mobilization of ILCs into the blood in response to inflammatory stimuli.

As outlined above, the recruitment of blood-borne ILCPs during infection may contribute to ILC heterogeneity within tissue. However, the signals activating blood-resident ILCs within tissue and recruiting them into the inflamed tissue from the circulation are unknown. This could involve tissue-derived signals sensed within the local vasculature and/or intra-tissue signals. Furthermore, the relative contribution of local expansion of resident ILCs vs. the recruitment of ILCPs to inflamed tissue is still unclear and may vary between tissues and the type of insult. For example, inflammatory signals could disrupt RANKL-RANK interactions, thereby allowing the local proliferation of CCR6 ${ }^{+}$ ILC3s (61).

\section{ILC MIGRATION IN CANCER}

Another largely unexplored area that warrants further investigation is ILC migration in cancer. The tumor microenvironment constitutes a unique metabolic milieu, resembling inflamed tissue. Among ILCs, NK cells are often the predominant population found in the tumor microenvironment, e.g., in human lung and colon cancer (30). Due to their cytotoxic activity, NK cells are a promising target for anti-cancer immunotherapy (133). However, in many human cancers, e.g., lung adenocarcinoma, NK cells are under-represented within the tumor compared to healthy tissue (134), especially the cytotoxic CD56 ${ }^{\text {dim }}$ subset (135). This suggests that NK cell recruitment to tumors is suboptimal and targeting NK cell migration could be a valuable strategy in cancer immunotherapy. Several chemokines and their respective receptors mediating $\mathrm{NK}$ cell migration to tumors have been identified, such as CXCL8-CXCR1/CXCR2, CXCL10-CXCR3, CXCL12-CXCR4, and they are being explored as clinical targets (136).

Whereas, a role for NK cells in controlling cancer growth and metastasis has been well-established, the function of other ILC subsets in cancer, especially in regards to migration, is poorly understood (133). In several hematological malignancies, human ILC1s, ILC2s, and ILC3s are increased in the blood compared to healthy individuals (133), supporting the notion that ILCs can be mobilized into the circulation during malignancy. There is also some evidence that circulating human ILC2s could contribute to immunosuppression in gastric cancer (137).

Furthermore, ILC3s with likely LTi function are enriched in solid tumors both in mice and humans. For example, NKp $46^{+}$ ILC3s invade B16 mouse melanoma expressing IL-12 (138). It was shown in the same model that lymphoid tissue-resident (splenic) Rorc ${ }^{\text {fate-map }+}$ ILCs have superior anti-tumor activity than intestinal or hepatic Rorc ${ }^{\text {fate }}-$ map + ILCs and Rorc fate-mapILC1s/NK cells (139). NKp46 ${ }^{+} \mathrm{CCR}^{+}{ }^{+} \mathrm{CXCR}^{+}{ }^{+}$ILC3s with LTi properties are also enriched in tumor-associated tertiary lymphoid structures in human non-small cell lung cancer (140). Both studies showed that tumor-associated ILC3s upregulate adhesion molecules on the tumor vasculature, which likely promotes anti-tumor immunity through the recruitment of $\mathrm{T}$ cells. These tertiary lymphoid structures are of interest because of their importance for $\mathrm{T}$ cell-mediated anti-tumor immunity and their general positive prognostic value for cancer outcome, e.g., in lung cancer (141). However, tumor-associated lymphoid structures may also promote cancer growth. For example, one study reported that high amounts of CCL21 recruit CD4 ${ }^{+}$ LTi cells to tumors in a CCR7-dependent manner, which is associated with the formation of tumor-promoting lymphoidlike stroma in melanoma (89). In a mouse model of breast cancer, it was also shown that CCL21 recruits CCR7-expressing ILC3s with an LTi phenotype $\left(\mathrm{CD} 4^{+} \mathrm{CCR} 6^{+}\right)$to the tumor environment (90). Furthermore, CXCL13 was required for the clustering of $\mathrm{CXCR}^{+}$ILC3s with mesenchymal stromal cells in the tumor microenvironment, which supported lymph node metastasis (90).

Interestingly, complementary to our findings in the intestine, it has recently been shown that oxysterol recognition through GPR183 is required for the development of iBALT (142), a common feature of active lung inflammation. However, this study did not determine the role of GPR183-expressing ILCs in this process. Overall, it seems plausible that the oxysterolGPR183 pathway could also be involved in the formation of tertiary lymphoid structures in cancer.

\section{CONCLUDING REMARKS}

ILCs maintain healthy organ function and it is increasingly recognized that ILC function is critically dependent on their trafficking to and localization within tissues. Accordingly, ILC migration and the mechanisms of ILC tissue recruitment are areas that are beginning to be explored in more depth. It is important to comprehensively identify the guidance cues and receptors that control ILC localization and motility in tissues. In the long-term, cell surface receptors regulating ILC migration to inflamed or malignant tissues could serve as new therapeutic targets for human diseases.

\section{AUTHOR CONTRIBUTIONS}

The author confirms being the sole contributor of this work and has approved it for publication.

\section{FUNDING}

TW was supported by a Junior Investigator Grant from the Center for Innovative Medicine and a faculty-funded career position at Karolinska Institutet as well as a grant from the Swedish Research Council. 


\section{REFERENCES}

1. Diefenbach A, Colonna M, Koyasu S. Development, differentiation, and diversity of innate lymphoid cells. Immunity. (2014) 41:354-65. doi: 10.1016/j.immuni.2014.09.005

2. Artis D, Spits H. The biology of innate lymphoid cells. Nature. (2015) 517:293-301. doi: 10.1038/nature14189

3. Eberl G, Colonna M, Di Santo JP, McKenzie AN. Innate lymphoid cells. Innate lymphoid cells: a new paradigm in immunology. Science. (2015) 348:aaa6566. doi: 10.1126/science.aaa6566

4. Serafini N, Vosshenrich CA, Di Santo JP. Transcriptional regulation of innate lymphoid cell fate. Nat Rev Immunol. (2015) 15:415-28. doi: 10.1038/nri3855

5. Vivier E, Artis D, Colonna M, Diefenbach A, Di Santo JP, Eberl G, et al. Innate lymphoid cells: 10 years on. Cell. (2018) 174:1054-66. doi: 10.1016/j.cell.2018.07.017

6. van de Pavert SA, Vivier E. Differentiation and function of group 3 innate lymphoid cells, from embryo to adult. Int Immunol. (2016) 28:35-42. doi: 10.1093/intimm/dxv052

7. Melo-Gonzalez F, Hepworth MR. Functional and phenotypic heterogeneity of group 3 innate lymphoid cells. Immunology. (2017) 150:265-75. doi: $10.1111 /$ imm. 12697

8. Constantinides MG, McDonald BD, Verhoef PA, Bendelac A. A committed precursor to innate lymphoid cells. Nature. (2014) 508:397-401. doi: 10.1038/nature13047

9. Possot C, Schmutz S, Chea S, Boucontet L, Louise A, Cumano A, et al. Notch signaling is necessary for adult, but not fetal, development of RORgammat(+) innate lymphoid cells. Nat Immunol. (2011) 12:949-58. doi: 10.1038/ni.2105

10. Sawa S, Cherrier M, Lochner M, Satoh-Takayama N, Fehling HJ, Langa F, et al. Lineage relationship analysis of RORgammat+ innate lymphoid cells. Science. (2010) 330:665-9. doi: 10.1126/science.1194597

11. Klose CS, Kiss EA, Schwierzeck V, Ebert K, Hoyler T, d'Hargues Y, et al. A T-bet gradient controls the fate and function of CCR6-RORgammat+ innate lymphoid cells. Nature. (2013) 494:261-5. doi: 10.1038/nature11813

12. Kiss EA, Vonarbourg C, Kopfmann S, Hobeika E, Finke D, Esser C, et al. Natural aryl hydrocarbon receptor ligands control organogenesis of intestinal lymphoid follicles. Science. (2011) 334:1561-5. doi: $10.1126 /$ science. 1214914

13. Lee JS, Cella M, McDonald KG, Garlanda C, Kennedy GD, Nukaya M, et al. AHR drives the development of gut ILC22 cells and postnatal lymphoid tissues via pathways dependent on and independent of Notch. Nat Immunol. (2011) 13:144-51. doi: 10.1038/ni.2187

14. Qiu J, Heller JJ, Guo X, Chen ZM, Fish K, Fu YX, et al. The aryl hydrocarbon receptor regulates gut immunity through modulation of innate lymphoid cells. Immunity. (2012) 36:92-104. doi: 10.1016/j.immuni.2011.11.011

15. van de Pavert SA, Ferreira M, Domingues RG, Ribeiro H, Molenaar R, Moreira-Santos L, et al. Maternal retinoids control type 3 innate lymphoid cells and set the offspring immunity. Nature. (2014) 508:123-7. doi: 10.1038/nature13158

16. Spencer SP, Wilhelm C, Yang Q, Hall JA, Bouladoux N, Boyd A, et al. Adaptation of innate lymphoid cells to a micronutrient deficiency promotes type 2 barrier immunity. Science. (2014) 343:432-7. doi: 10.1126/science.1247606

17. Goverse G, Labao-Almeida C, Ferreira M, Molenaar R, Wahlen S, Konijn T, et al. Vitamin A controls the presence of RORgamma+ innate lymphoid cells and lymphoid tissue in the small intestine. J Immunol. (2016) 196:5148-55. doi: 10.4049/jimmunol.1501106

18. Mebius RE, Rennert P, Weissman IL. Developing lymph nodes collect CD4+CD3- LTbeta+ cells that can differentiate to APC, NK cells, and follicular cells but not $\mathrm{T}$ or B cells. Immunity. (1997) 7:493-504. doi: 10.1016/S1074-7613(00)80371-4

19. Eberl G, Littman DR. Thymic origin of intestinal alphabeta $T$ cells revealed by fate mapping of RORgammat+ cells. Science. (2004) 305:248-51. doi: 10.1126/science. 1096472

20. Eberl G, Marmon S, Sunshine MJ, Rennert PD, Choi Y, Littman DR. An essential function for the nuclear receptor RORgamma(t) in the generation of fetal lymphoid tissue inducer cells. Nat Immunol. (2004) 5:64-73. doi: $10.1038 /$ ni1022
21. Emgard J, Kammoun H, Garcia-Cassani B, Chesne J, Parigi SM, Jacob JM, et al. Oxysterol sensing through the receptor GPR183 promotes the lymphoidtissue-inducing function of innate lymphoid cells and colonic inflammation. Immunity. (2018) 48:120-32 e128. doi: 10.1016/j.immuni.2017.11.020

22. van de Pavert SA, Mebius RE. New insights into the development of lymphoid tissues. Nat Rev Immunol. (2010) 10:664-74. doi: 10.1038/nri2832

23. Randall TD, Mebius RE. The development and function of mucosal lymphoid tissues: a balancing act with micro-organisms. Mucosal Immunol. (2014) 7:455-66. doi: 10.1038/mi.2014.11

24. McKenzie ANJ, Spits H, Eberl G. Innate lymphoid cells in inflammation and immunity. Immunity. (2014) 41:366-74. doi: 10.1016/j.immuni.2014.09.006

25. Sonnenberg GF, Artis D. Innate lymphoid cells in the initiation, regulation and resolution of inflammation. Nat Med. (2015) 21:698-708. doi: $10.1038 / \mathrm{nm} .3892$

26. Ebbo M, Crinier A, Vely F, Vivier E. Innate lymphoid cells: major players in inflammatory diseases. Nat Rev Immunol. (2017) 17:665-78. doi: 10.1038/nri.2017.86

27. Mjosberg JM, Trifari S, Crellin NK, Peters CP, van Drunen CM, Piet B, et al. Human IL-25- and IL-33-responsive type 2 innate lymphoid cells are defined by expression of CRTH2 and CD161. Nat Immunol. (2011) 12:1055-62. doi: $10.1038 /$ ni.2104

28. Klose CSN, Flach M, Mohle L, Rogell L, Hoyler T, Ebert K, et al. Differentiation of type 1 ILCs from a common progenitor to all helper-like innate lymphoid cell lineages. Cell. (2014) 157:340-56. doi: 10.1016/j.cell.2014.03.030

29. Robinette ML, Fuchs A, Cortez VS, Lee JS, Wang Y, Durum SK, et al. Transcriptional programs define molecular characteristics of innate lymphoid cell classes and subsets. Nat Immunol. (2015) 16:306-17. doi: 10.1038/ni.3094

30. Simoni Y, Fehlings M, Kloverpris HN, McGovern N, Koo SL, Loh CY, et al. Human innate lymphoid cell subsets possess tissue-type based heterogeneity in phenotype and frequency. Immunity. (2017) 46:148-61. doi: 10.1016/j.immuni.2016.11.005

31. Yudanin NA, Schmitz F, Flamar AL, Thome JJC, Tait Wojno E, Moeller JB, et al. Spatial and temporal mapping of human innate lymphoid cells reveals elements of tissue specificity. Immunity. (2019) 50:505-19 e504. doi: 10.1016/j.immuni.2019.01.012

32. Kim CH, Hashimoto-Hill S, Kim M. Migration and tissue tropism of innate lymphoid cells. Trends Immunol. (2016) 37:68-79. doi: 10.1016/j.it.2015.11.003

33. Monticelli LA, Sonnenberg GF, Abt MC, Alenghat T, Ziegler CG, Doering TA, et al. Innate lymphoid cells promote lung-tissue homeostasis after infection with influenza virus. Nat Immunol. (2011) 12:1045-54. doi: 10.1038/ni.2131

34. Sawa S, Lochner M, Satoh-Takayama N, Dulauroy S, Berard M, Kleinschek $\mathrm{M}$, et al. RORgammat+ innate lymphoid cells regulate intestinal homeostasis by integrating negative signals from the symbiotic microbiota. Nat Immunol. (2011) 12:320-6. doi: 10.1038/ni.2002

35. Bernink JH, Peters CP, Munneke M, te Velde AA, Meijer SL, Weijer K, et al. Human type 1 innate lymphoid cells accumulate in inflamed mucosal tissues. Nat Immunol. (2013) 14:221-9. doi: 10.1038/ni.2534

36. Gomez de Aguero M, Ganal-Vonarburg SC, Fuhrer T, Rupp S, Uchimura $\mathrm{Y}, \mathrm{Li} \mathrm{H}$, et al. The maternal microbiota drives early postnatal innate immune development. Science. (2016) 351:1296-302. doi: 10.1126/science. $\operatorname{aad} 2571$

37. Stier MT, Zhang J, Goleniewska K, Cephus JY, Rusznak M, Wu L, et al. IL-33 promotes the egress of group 2 innate lymphoid cells from the bone marrow. J Exp Med. (2018) 215:263-81. doi: 10.1084/jem.20170449

38. Bando JK, Liang HE, Locksley RM. Identification and distribution of developing innate lymphoid cells in the fetal mouse intestine. Nat Immunol. (2015) 16:153-60. doi: 10.1038/ni.3057

39. Gasteiger G, Fan X, Dikiy S, Lee SY, Rudensky AY. Tissue residency of innate lymphoid cells in lymphoid and nonlymphoid organs. Science. (2015) 350:981-5. doi: 10.1126/science.aac9593

40. Lim AI, Li Y, Lopez-Lastra S, Stadhouders R, Paul F, Casrouge A, et al. Systemic human ILC precursors provide a substrate for tissue ILC differentiation. Cell. (2017) 168:1086-100 e1010. doi: 10.1016/j.cell.2017.02.021 
41. Huang Y, Mao K, Chen X, Sun MA, Kawabe T, Li W, et al. S1P-dependent interorgan trafficking of group 2 innate lymphoid cells supports host defense. Science. (2018) 359:114-9. doi: 10.1126/science.aam5809

42. Bar-Ephraim YE, Koning JJ, Burniol Ruiz E, Konijn T, Mourits VP, Lakeman KA, et al. CD62L Is a Functional and phenotypic marker for circulating innate lymphoid cell precursors. J Immunol. (2019) 202:171-82. doi: 10.4049/jimmunol.1701153

43. Dutton EE, Gajdasik DW, Willis C, Fiancette R, Bishop EL, Camelo $\mathrm{A}$, et al. Peripheral lymph nodes contain migratory and resident innate lymphoid cell populations. Sci Immunol. (2019) 4:eaau8082. doi: 10.1126/sciimmunol.aau8082

44. Collins PL, Cella M, Porter SI, Li S, Gurewitz GL, Hong HS, et al. Gene regulatory programs conferring phenotypic identities to human NK cells. Cell. (2019) 176:348-60 e312. doi: 10.1016/j.cell.2018.11.045

45. Kanamori Y, Ishimaru K, Nanno M, Maki K, Ikuta K, Nariuchi H, et al. Identification of novel lymphoid tissues in murine intestinal mucosa where clusters of c-kit + IL-7R+ Thyl+ lympho-hemopoietic progenitors develop. J Exp Med. (1996) 184:1449-59. doi: 10.1084/jem.184.4.1449

46. Hamada H, Hiroi T, Nishiyama Y, Takahashi H, Masunaga Y, Hachimura $\mathrm{S}$, et al. Identification of multiple isolated lymphoid follicles on the antimesenteric wall of the mouse small intestine. J Immunol. (2002) 168:5764. doi: 10.4049/jimmunol.168.1.57

47. Satoh-Takayama N, Vosshenrich CA, Lesjean-Pottier S, Sawa S, Lochner M, Rattis F, et al. Microbial flora drives interleukin 22 production in intestinal $\mathrm{NKp} 46+$ cells that provide innate mucosal immune defense. Immunity. (2008) 29:958-70. doi: 10.1016/j.immuni.2008.11.001

48. Luci C, Reynders A, Ivanov II, Cognet C, Chiche L, Chasson L, et al. Influence of the transcription factor RORgammat on the development of NKp46+ cell populations in gut and skin. Nat Immunol. (2009) 10:75-82. doi: $10.1038 /$ ni.1681

49. Sanos SL, Bui VL, Mortha A, Oberle K, Heners C, Johner C, et al. RORgammat and commensal microflora are required for the differentiation of mucosal interleukin 22-producing NKp46+ cells. Nat Immunol. (2009) 10:83-91. doi: 10.1038/ni.1684

50. Fuchs A, Vermi W, Lee JS, Lonardi S, Gilfillan S, Newberry RD, et al. Intraepithelial type 1 innate lymphoid cells are a unique subset of IL-12- and IL-15-responsive IFN-gamma-producing cells. Immunity. (2013) 38:769-81. doi: 10.1016/j.immuni.2013.02.010

51. Tsuji M, Suzuki K, Kitamura H, Maruya M, Kinoshita K, Ivanov II, et al. Requirement for lymphoid tissue-inducer cells in isolated follicle formation and $\mathrm{T}$ cell-independent immunoglobulin A generation in the gut. Immunity. (2008) 29:261-71. doi: 10.1016/j.immuni.2008.05.014

52. Kruglov AA, Grivennikov SI, Kuprash DV, Winsauer C, Prepens S, Seleznik GM, et al. Nonredundant function of soluble LTalpha3 produced by innate lymphoid cells in intestinal homeostasis. Science. (2013) 342:1243-6. doi: 10.1126/science.1243364

53. Macpherson AJ, Yilmaz B, Limenitakis JP, Ganal-Vonarburg SC. IgA function in relation to the intestinal microbiota. Annu Rev Immunol. (2018) 36:359-81. doi: 10.1146/annurev-immunol-042617-053238

54. Sonnenberg GF, Monticelli LA, Alenghat T, Fung TC, Hutnick NA, Kunisawa J, et al. Innate lymphoid cells promote anatomical containment of lymphoid-resident commensal bacteria. Science. (2012) 336:1321-5. doi: $10.1126 /$ science. 1222551

55. Hanash AM, Dudakov JA, Hua G, O'Connor MH, Young LF, Singer NV, et al. Interleukin-22 protects intestinal stem cells from immune-mediated tissue damage and regulates sensitivity to graft versus host disease. Immunity. (2012) 37:339-50. doi: 10.1016/j.immuni.2012.05.028

56. Aparicio-Domingo P, Romera-Hernandez M, Karrich JJ, Cornelissen F, Papazian N, Lindenbergh-Kortleve DJ, et al. Type 3 innate lymphoid cells maintain intestinal epithelial stem cells after tissue damage. J Exp Med. (2015) 212:1783-91. doi: 10.1084/jem.20150318

57. Lindemans CA, Calafiore M, Mertelsmann AM, O'Connor MH, Dudakov JA, Jenq RR, et al. Interleukin-22 promotes intestinal-stem-cell-mediated epithelial regeneration. Nature. (2015) 528:560-4. doi: 10.1038/nature16460

58. Satoh-Takayama N, Serafini N, Verrier T, Rekiki A, Renauld JC, Frankel G, et al. The chemokine receptor CXCR6 controls the functional topography of interleukin-22 producing intestinal innate lymphoid cells. Immunity. (2014) 41:776-88. doi: 10.1016/j.immuni.2014.10.007
59. Savage AK, Liang HE, Locksley RM. The development of steady-state activation hubs between adult LTi ILC3s and primed macrophages in small intestine. J Immunol. (2017) 199:1912-22. doi: 10.4049/jimmunol.1700155

60. Pearson C, Thornton EE, McKenzie B, Schaupp AL, Huskens N, Griseri T, et al. ILC3 GM-CSF production and mobilisation orchestrate acute intestinal inflammation. Elife. (2016) 5:e10066. doi: 10.7554/eLife.10066

61. Bando JK, Gilfillan S, Song C, McDonald KG, Huang SC, Newberry RD, et al. The tumor necrosis factor superfamily member RANKL suppresses effector cytokine production in group 3 innate lymphoid cells. Immunity. (2018) 48:1208-19 e1204. doi: 10.1016/j.immuni.2018.04.012

62. Hoorweg K, Narang P, Li Z, Thuery A, Papazian N, Withers DR, et al. A stromal cell niche for human and mouse type 3 innate lymphoid cells. $J$ Immunol. (2015) 195:4257-63. doi: 10.4049/jimmunol.1402584

63. Nussbaum JC, Van Dyken SJ, von Moltke J, Cheng LE, Mohapatra A, Molofsky $\mathrm{AB}$, et al. Type 2 innate lymphoid cells control eosinophil homeostasis. Nature. (2013) 502:245-8. doi: 10.1038/nature12526

64. Dahlgren MW, Jones SW, Cautivo KM, Dubinin A, Ortiz-Carpena JF, Farhat $\mathrm{S}$, et al. Adventitial stromal cells define group 2 innate lymphoid cell tissue niches. Immunity. (2019). doi: 10.1016/j.immuni.2019.02.002

65. Sui P, Wiesner DL, Xu J, Zhang Y, Lee J, Van Dyken S, et al. Pulmonary neuroendocrine cells amplify allergic asthma responses. Science. (2018) 360:eaan8546. doi: 10.1126/science.aan8546

66. Ibiza S, Garcia-Cassani B, Ribeiro H, Carvalho T, Almeida L, Marques $\mathrm{R}$, et al. Glial-cell-derived neuroregulators control type 3 innate lymphoid cells and gut defence. Nature. (2016) 535:440-3. doi: 10.1038/nature 18644

67. Cardoso V, Chesne J, Ribeiro H, Garcia-Cassani B, Carvalho T, Bouchery T, et al. Neuronal regulation of type 2 innate lymphoid cells via neuromedin $\mathrm{U}$. Nature. (2017) 549:277-81. doi: 10.1038/nature23469

68. Dalli J, Colas RA, Arnardottir H, Serhan CN. Vagal regulation of group 3 innate lymphoid cells and the immunoresolvent PCTR1 controls infection resolution. Immunity. (2017) 46:92-105. doi: 10.1016/j.immuni.2016.12.009

69. Klose CSN, Mahlakoiv T, Moeller JB, Rankin LC, Flamar AL, Kabata H, et al. The neuropeptide neuromedin U stimulates innate lymphoid cells and type 2 inflammation. Nature. (2017) 549:282-6. doi: 10.1038/nature23676

70. Wallrapp A, Riesenfeld SJ, Burkett PR, Abdulnour RE, Nyman J, Dionne $\mathrm{D}$, et al. The neuropeptide NMU amplifies ILC2-driven allergic lung inflammation. Nature. (2017) 549:351-6. doi: 10.1038/nature24029

71. Moriyama S, Brestoff JR, Flamar AL, Moeller JB, Klose CSN, Rankin $\mathrm{LC}$, et al. beta2-adrenergic receptor-mediated negative regulation of group 2 innate lymphoid cell responses. Science. (2018) 359:1056-61. doi: 10.1126/science.aan4829

72. Ricardo-Gonzalez RR, Van Dyken SJ, Schneider C, Lee J, Nussbaum JC, Liang $\mathrm{HE}$, et al. Tissue signals imprint ILC2 identity with anticipatory function. Nat Immunol. (2018) 19:1093-9. doi: 10.1038/s41590-018-0201-4

73. Bernink JH, Krabbendam L, Germar K, de Jong E, Gronke K, Kofoed-Nielsen $\mathrm{M}$, et al. Interleukin-12 and-23 control plasticity of CD127(+) group 1 and group 3 innate lymphoid cells in the intestinal lamina propria. Immunity. (2015) 43:146-60. doi: 10.1016/j.immuni.2015.06.019

74. Bal SM, Bernink JH, Nagasawa M, Groot J, Shikhagaie MM, Golebski K, et al. IL-1beta, IL-4 and IL-12 control the fate of group 2 innate lymphoid cells in human airway inflammation in the lungs. Nat Immunol. (2016) 17:636-45. doi: 10.1038/ni.3444

75. Ohne Y, Silver JS, Thompson-Snipes L, Collet MA, Blanck JP, Cantarel BL, et al. IL-1 is a critical regulator of group 2 innate lymphoid cell function and plasticity. Nat Immunol. (2016) 17:646-55. doi: 10.1038/ni.3447

76. Silver JS, Kearley J, Copenhaver AM, Sanden C, Mori M, Yu L, et al. Inflammatory triggers associated with exacerbations of COPD orchestrate plasticity of group 2 innate lymphoid cells in the lungs. Nat Immunol. (2016) 17:626-35. doi: 10.1038/ni.3443

77. Withers DR, Hepworth MR. Group 3 innate lymphoid cells: communications hubs of the intestinal immune system. Front Immunol. (2017) 8:1298. doi: 10.3389/fimmu.2017.01298

78. Hepworth MR, Monticelli LA, Fung TC, Ziegler CG, Grunberg S, Sinha R, et al. Innate lymphoid cells regulate CD4+ T-cell responses to intestinal commensal bacteria. Nature. (2013) 498:113-7. doi: 10.1038/nature12240

79. Hepworth MR, Fung TC, Masur SH, Kelsen JR, McConnell FM, Dubrot J, et al. Immune tolerance. Group 3 innate lymphoid cells mediate intestinal 
selection of commensal bacteria-specific CD4(+) T cells. Science. (2015) 348:1031-5. doi: 10.1126/science.aaa4812

80. Oliphant CJ, Hwang YY, Walker JA, Salimi M, Wong SH, Brewer JM, et al. MHCII-mediated dialog between group 2 innate lymphoid cells and CD4(+) T cells potentiates type 2 immunity and promotes parasitic helminth expulsion. Immunity. (2014) 41:283-95. doi: 10.1016/j.immuni.2014.06.016

81. Halim TYF, Rana BMJ, Walker JA, Kerscher B, Knolle MD, Jolin HE, et al. Tissue-restricted adaptive type 2 immunity is orchestrated by expression of the costimulatory molecule OX40L on group 2 innate lymphoid cells. Immunity. (2018) 48:1195-207 e1196. doi: 10.1016/j.immuni.2018.05.003

82. Kim MY, Toellner KM, White A, McConnell FM, Gaspal FM, Parnell $\mathrm{SM}$, et al. Neonatal and adult CD4+ CD3- cells share similar gene expression profile, and neonatal cells up-regulate OX40 ligand in response to TL1A. (TNFSF15). J Immunol. (2006) 177:3074-81. doi: 10.4049/jimmunol.177.5.3074

83. Martin CE, Spasova DS, Frimpong-Boateng K, Kim HO, Lee M, Kim KS, et al. Interleukin-7 availability is maintained by a hematopoietic cytokine sink comprising innate lymphoid cells and T cells. Immunity. (2017) 47:171-82 e174. doi: 10.1016/j.immuni.2017.07.005

84. Mackley EC, Houston S, Marriott CL, Halford EE, Lucas B, Cerovic V, et al. CCR7-dependent trafficking of RORgamma(+) ILCs creates a unique microenvironment within mucosal draining lymph nodes. Nat Commun. (2015) 6:5862. doi: $10.1038 /$ ncomms6862

85. Kim MH, Taparowsky EJ, Kim CH. Retinoic acid differentially regulates the migration of innate lymphoid cell subsets to the gut. Immunity. (2015) 43:107-19. doi: 10.1016/j.immuni.2015.06.009

86. Gury-BenAri M, Thaiss CA, Serafini N, Winter DR, Giladi A, LaraAstiaso D, et al. The spectrum and regulatory landscape of intestinal innate lymphoid cells are shaped by the microbiome. Cell. (2016) 166:1231-46 e1213. doi: $10.1016 /$ j.cell.2016.07.043

87. Kobayashi T, Voisin B, Kim DY, Kennedy EA, Jo JH, Shih HY, et al. Homeostatic control of sebaceous glands by innate lymphoid cells regulates commensal bacteria equilibrium. Cell. (2019) 176:982-97 e916. doi: 10.1016/j.cell.2018.12.031

88. van de Pavert SA, Olivier BJ, Goverse G, Vondenhoff MF, Greuter M, Beke $\mathrm{P}$, et al. Chemokine CXCL13 is essential for lymph node initiation and is induced by retinoic acid and neuronal stimulation. Nat Immunol. (2009) 10:1193-9. doi: 10.1038/ni.1789

89. Shields JD, Kourtis IC, Tomei AA, Roberts JM, Swartz MA. Induction of lymphoidlike stroma and immune escape by tumors that express the chemokine CCL21. Science. (2010) 328:749-52. doi: 10.1126/science.1185837

90. Irshad S, Flores-Borja F, Lawler K, Monypenny J, Evans R, Male $\mathrm{V}$, et al. RORgammat(+) innate lymphoid cells promote lymph node metastasis of breast cancers. Cancer Res. (2017) 77:1083-96. doi: 10.1158/0008-5472.CAN-16-0598

91. Ardain A, Domingo-Gonzalez R, Das S, Kazer SW, Howard NC, Singh A, et al. Group 3 innate lymphoid cells mediate early protective immunity against tuberculosis. Nature. (2019) 570:528-32. doi: 10.1038/s41586-019-1276-2

92. Chea S, Possot C, Perchet T, Petit M, Cumano A, Golub R. CXCR6 expression is important for retention and circulation of ILC precursors. Mediat Inflamm. (2015) 2015:368427. doi: 10.1155/2015/368427

93. Paust S, Gill HS, Wang BZ, Flynn MP, Moseman EA, Senman B, et al. Critical role for the chemokine receptor CXCR6 in NK cell-mediated antigenspecific memory of haptens and viruses. Nat Immunol. (2010) 11:1127-35. doi: 10.1038/ni.1953

94. Kim SH, Cho BH, Kiyono H, Jang YS. Microbiota-derived butyrate suppresses group 3 innate lymphoid cells in terminal ileal Peyer's patches. Sci Rep. (2017) 7:3980. doi: 10.1038/s41598-017-02729-6

95. Chu C, Moriyama S, Li Z, Zhou L, Flamar AL, Klose CSN, et al. Antimicrobial functions of group 3 innate lymphoid cells in gut-associated lymphoid tissues are regulated by G-protein-coupled receptor 183. Cell Rep. (2018) 23:3750-8. doi: 10.1016/j.celrep.2018.05.099

96. Melo-Gonzalez F, Kammoun H, Evren E, Dutton EE, Papadopoulou M, Bradford BM, et al. Antigen-presenting ILC3 regulate T cell-dependent IgA responses to colonic mucosal bacteria. J Exp Med. (2019) 216, 728-42. doi: $10.1084 /$ jem.20180871
97. Walzer T, Chiossone L, Chaix J, Calver A, Carozzo C, Garrigue-Antar L, et al. Natural killer cell trafficking in vivo requires a dedicated sphingosine 1-phosphate receptor. Nat Immunol. (2007) 8:1337-44. doi: 10.1038/ni1523

98. Wojno ED, Monticelli LA, Tran SV, Alenghat T, Osborne LC, Thome JJ, et al. The prostaglandin $\mathrm{D}(2)$ receptor $\mathrm{CRTH} 2$ regulates accumulation of group 2 innate lymphoid cells in the inflamed lung. Mucosal Immunol. (2015) 8:1313-23. doi: 10.1038/mi.2015.21

99. Shikhagaie MM, Bjorklund AK, Mjosberg J, Erjefalt JS, Cornelissen AS, Ros XR, et al. Neuropilin-1 is expressed on lymphoid tissue residing LTilike group 3 innate lymphoid cells and associated with ectopic lymphoid aggregates. Cell Rep. (2017) 18:1761-73. doi: 10.1016/j.celrep.2017.01.063

100. Hoyler T, Klose CS, Souabni A, Turqueti-Neves A, Pfeifer D, Rawlins EL, et al. The transcription factor GATA-3 controls cell fate and maintenance of type 2 innate lymphoid cells. Immunity. (2012) 37:634-48. doi: 10.1016/j.immuni.2012.06.020

101. Li BWS, Stadhouders R, de Bruijn MJW, Lukkes M, Beerens D, Brem MD, et al. Group 2 innate lymphoid cells exhibit a dynamic phenotype in allergic airway inflammation. Front Immunol. (2017) 8:1684. doi: 10.3389/fimmu.2017.01684

102. Bjorklund AK, Forkel M, Picelli S, Konya V, Theorell J, Friberg D, et al. The heterogeneity of human $\mathrm{CD} 127(+)$ innate lymphoid cells revealed by singlecell RNA sequencing. Nat Immunol. (2016) 17:451-60. doi: 10.1038/ni.3368

103. Mebius RE, Streeter PR, Michie S, Butcher EC, Weissman IL. A developmental switch in lymphocyte homing receptor and endothelial vascular addressin expression regulates lymphocyte homing and permits CD4+ CD3- cells to colonize lymph nodes. Proc Natl Acad Sci USA. (1996) 93:11019-24. doi: 10.1073/pnas.93.20.11019

104. Veiga-Fernandes H, Coles MC, Foster KE, Patel A, Williams A, Natarajan D, et al. Tyrosine kinase receptor RET is a key regulator of Peyer's patch organogenesis. Nature. (2007) 446:547-51. doi: 10.1038/nature05597

105. Cherrier M, Sawa S, Eberl G. Notch, Id2, and RORgammat sequentially orchestrate the fetal development of lymphoid tissue inducer cells. J Exp Med. (2012) 209:729-40. doi: 10.1084/jem.20111594

106. Ginhoux F, Guilliams M. Tissue-resident macrophage ontogeny and homeostasis. Immunity. (2016) 44:439-49. doi: 10.1016/j.immuni.2016.02.024

107. Perdiguero EG, Geissmann F. The development and maintenance of resident macrophages. Nat Immunol. (2016) 17:2-8. doi: 10.1038/ni.3341

108. Kim SV, Xiang WV, Kwak C, Yang Y, Lin XW, Ota M, et al. GPR15-mediated homing controls immune homeostasis in the large intestine mucosa. Science. (2013) 340:1456-9. doi: 10.1126/science.1237013

109. Montaldo E, Teixeira-Alves LG, Glatzer T, Durek P, Stervbo U, Hamann $\mathrm{W}$, et al. Human RORgammat $(+) \mathrm{CD} 34(+)$ cells are lineage-specified progenitors of group 3 RORgammat(+) innate lymphoid cells. Immunity. (2014) 41:988-1000. doi: 10.1016/j.immuni.2014.11.010

110. Scoville SD, Mundy-Bosse BL, Zhang MH, Chen L, Zhang X, Keller KA, et al. A progenitor cell expressing transcription factor RORgammat generates all human innate lymphoid cell subsets. Immunity. (2016) 44:1140-50. doi: 10.1016/j.immuni.2016.04.007

111. Lim AI, Di Santo JP. ILC-poiesis: ensuring tissue ILC differentiation at the right place and time. Eur J Immunol. (2019) 49:11-8. doi: 10.1002/eji.201747294

112. Cyster JG, Schwab SR. Sphingosine-1-phosphate and lymphocyte egress from lymphoid organs. Annu Rev Immunol. (2012) 30:69-94. doi: 10.1146/annurev-immunol-020711-075011

113. Eken A, Yetkin MF, Vural A, Okus FZ, Erdem S, Azizoglu ZB, et al. Fingolimod alters tissue distribution and cytokine production of human and murine innate lymphoid cells. Front Immunol. (2019) 10:217. doi: $10.3389 /$ fimmu.2019.00217

114. Bar-Ephraim YE, Cornelissen F, Papazian N, Konijn T, Hoogenboezem RM, Sanders MA, et al. Cross-tissue transcriptomic analysis of human secondary lymphoid organ-residing ILC3s reveals a quiescent state in the absence of inflammation. Cell Rep. (2017) 21:823-33. doi: 10.1016/j.celrep.2017.09.070

115. Szabo PA, Miron M, Farber DL. Location, location, location: tissue resident memory T cells in mice and humans. Sci Immunol. (2019) 4:eaas9673. doi: 10.1126/sciimmunol.aas 9673 
116. Shiow LR, Rosen DB, Brdickova N, Xu Y, An J, Lanier LL, et al. CD69 acts downstream of interferon-alpha/beta to inhibit S1P1 and lymphocyte egress from lymphoid organs. Nature. (2006) 440:540-4. doi: 10.1038/nature04606

117. Roediger B, Kyle R, Yip KH, Sumaria N, Guy TV, Kim BS, et al. Cutaneous immunosurveillance and regulation of inflammation by group 2 innate lymphoid cells. Nat Immunol. (2013) 14:564-73. doi: 10.1038/ni.2584

118. Cyster JG, Dang EV, Reboldi A, Yi T. 25-Hydroxycholesterols in innate and adaptive immunity. Nat Rev Immunol. (2014) 14:731-43. doi: $10.1038 /$ nri3755

119. Willinger T. Oxysterols in intestinal immunity and inflammation. J Intern Med. (2019) 285:367-80. doi: 10.1111/joim.12855

120. Wyss A, Raselli T, Perkins N, Ruiz F, Schmelczer G, Klinke G, et al. The EBI2-oxysterol axis promotes the development of intestinal lymphoid structures and colitis. Mucosal Immunol. (2019) 12:733-45. doi: 10.1038/s41385-019-0140-x

121. McDonald KG, McDonough JS, Wang C, Kucharzik T, Williams IR, Newberry RD. CC chemokine receptor 6 expression by B lymphocytes is essential for the development of isolated lymphoid follicles. Am J Pathol. (2007) 170:1229-40. doi: 10.2353/ajpath.2007.060817

122. Baptista AP, Olivier BJ, Goverse G, Greuter M, Knippenberg M, Kusser $\mathrm{K}$, et al. Colonic patch and colonic SILT development are independent and differentially regulated events. Mucosal Immunol. (2013) 6:511-21. doi: $10.1038 / \mathrm{mi} .2012 .90$

123. Xue L, Salimi M, Panse I, Mjosberg JM, McKenzie AN, Spits H, et al. Prostaglandin D2 activates group 2 innate lymphoid cells through chemoattractant receptor-homologous molecule expressed on TH2 cells. $J$ Allergy Clin Immunol. (2014) 133:1184-94. doi: 10.1016/j.jaci.2013.10.056

124. Barnig C, Cernadas M, Dutile S, Liu X, Perrella MA, Kazani S, et al. Lipoxin A4 regulates natural killer cell and type 2 innate lymphoid cell activation in asthma. Sci Transl Med. (2013) 5:174ra126. doi: $10.1126 /$ scitranslmed.3004812

125. Fung TC, Bessman NJ, Hepworth MR, Kumar N, Shibata N, Kobuley D, et al. Lymphoid-tissue-resident commensal bacteria promote members of the IL-10 cytokine family to establish mutualism. Immunity. (2016) 44:634-46. doi: 10.1016/j.immuni.2016.02.019

126. Kim HY, Lee HJ, Chang YJ, Pichavant M, Shore SA, Fitzgerald KA, et al. Interleukin-17-producing innate lymphoid cells and the NLRP3 inflammasome facilitate obesity-associated airway hyperreactivity. Nat Med. (2014) 20:54-61. doi: 10.1038/nm.3423

127. Hams E, Armstrong ME, Barlow JL, Saunders SP, Schwartz C, Cooke G, et al. IL-25 and type 2 innate lymphoid cells induce pulmonary fibrosis. Proc Natl Acad Sci USA. (2014) 111:367-72. doi: 10.1073/pnas.1315854111

128. Scandella E, Bolinger B, Lattmann E, Miller S, Favre S, Littman DR, et al. Restoration of lymphoid organ integrity through the interaction of lymphoid tissue-inducer cells with stroma of the T cell zone. Nat Immunol. (2008) 9:667-75. doi: 10.1038/ni.1605

129. Dudakov JA, Hanash AM, Jenq RR, Young LF, Ghosh A, Singer NV, et al. Interleukin-22 drives endogenous thymic regeneration in mice. Science. (2012) 336:91-5. doi: 10.1126/science.1218004

130. Mjosberg J, Rao A. Lung inflammation originating in the gut. Science. (2018) 359:36-7. doi: 10.1126/science.aar4301

131. Munneke JM, Bjorklund AT, Mjosberg JM, Garming-Legert K, Bernink $\mathrm{JH}$, Blom B, et al. Activated innate lymphoid cells are associated with a reduced susceptibility to graft-versus-host disease. Blood. (2014) 124:812-21. doi: 10.1182/blood-2013-11-536888

132. Bartemes KR, Kephart GM, Fox SJ, Kita H. Enhanced innate type 2 immune response in peripheral blood from patients with asthma. J Allergy Clin Immunol. (2014) 134:671-8 e674. doi: 10.1016/j.jaci.2014.06.024

133. Chiossone L, Dumas PY, Vienne M, Vivier E. Natural killer cells and other innate lymphoid cells in cancer. Nat Rev Immunol. (2018) 18:671-88. doi: 10.1038/s41577-018-0061-z

134. Lavin Y, Kobayashi S, Leader A, Amir ED, Elefant N, Bigenwald C, et al. Innate immune landscape in early lung adenocarcinoma by paired single-cell analyses. Cell. (2017) 169:750-65 e717. doi: 10.1016/j.cell.2017.04.014

135. Castriconi R, Carrega P, Dondero A, Bellora F, Casu B, Regis S, et al. Molecular mechanisms directing migration and retention of natural killer cells in human tissues. Front Immunol. (2018) 9:2324. doi: 10.3389/fimmu.2018.02324

136. Susek KH, Karvouni M, Alici E, Lundqvist A. The role of CXC chemokine receptors 1-4 on immune cells in the tumor microenvironment. Front Immunol. (2018) 9:2159. doi: 10.3389/fimmu.2018.02159

137. Bie Q, Zhang P, Su Z, Zheng D, Ying X, Wu Y, et al. Polarization of ILC2s in peripheral blood might contribute to immunosuppressive microenvironment in patients with gastric cancer. J Immunol Res. (2014) 2014:923135. doi: 10.1155/2014/923135

138. Eisenring M, vom Berg J, Kristiansen G, Saller E, Becher B. IL-12 initiates tumor rejection via lymphoid tissue-inducer cells bearing the natural cytotoxicity receptor NKp46. Nat Immunol. (2010) 11:1030-8. doi: 10.1038/ni.1947

139. Nussbaum K, Burkhard SH, Ohs I, Mair F, Klose CSN, Arnold SJ, et al. Tissue microenvironment dictates the fate and tumor-suppressive function of type 3 ILCs. J Exp Med. (2017) 214:2331-47. doi: 10.1084/jem.201 62031

140. Carrega P, Loiacono F, Di Carlo E, Scaramuccia A, Mora M, Conte $\mathrm{R}$, et al. NCR(+)ILC3 concentrate in human lung cancer and associate with intratumoral lymphoid structures. Nat Commun. (2015) 6:8280. doi: $10.1038 /$ ncomms 9280

141. Colbeck EJ, Ager A, Gallimore A, Jones GW. Tertiary lymphoid structures in cancer: drivers of antitumor immunity, immunosuppression, or bystander sentinels in disease? Front Immunol. (2017) 8:1830. doi: 10.3389/fimmu.2017.01830

142. Jia J, Conlon TM, Sarker RS, Tasdemir D, Smirnova NF, Srivastava B, et al. Cholesterol metabolism promotes B-cell positioning during immune pathogenesis of chronic obstructive pulmonary disease. EMBO Mol Med. (2018) 10:e8349. doi: 10.15252/emmm.201708349

Conflict of Interest Statement: The author declares that the research was conducted in the absence of any commercial or financial relationships that could be construed as a potential conflict of interest.

Copyright (c) 2019 Willinger. This is an open-access article distributed under the terms of the Creative Commons Attribution License (CC BY). The use, distribution or reproduction in other forums is permitted, provided the original author(s) and the copyright owner(s) are credited and that the original publication in this journal is cited, in accordance with accepted academic practice. No use, distribution or reproduction is permitted which does not comply with these terms. 